\title{
The Ongoing Erosion of Division of Labour Spells Doom for Healthcare Delivery!
}

\author{
Mister Seun Ayoade* \\ Independent Researcher. Alumnus, College of Medicine University of Ibadan, Oyo State, Nigeria \\ *Corresponding author: Mister Seun Ayoade, Independent Researcher. Alumnus, College of Medicine University of Ibadan, Oyo State, \\ Nigeria
}

\begin{abstract}
Before the industrial revolution, in Europe and The United States of America, a client could walk into a barbershop, have a shave, a haircut, a painful boil lacerated -and have some of his blood drained off to boot! Barbers were called "barber-surgeons" and men without a medical degree-in fact men without hardly a rudimentary education-were allowed to operate. In those days as well, children of the wealthy could buy commissions into the army and navy and become overnight army and navy officers-without ever having set foot in a military academy! Those were also the days when men read law books at home or apprenticed with lawyers, showed up for exams and received law degrees without ever setting foot on a college campus or attending a single lecture!
\end{abstract}

\section{Introduction}

Is history not repeating itself today? The explosion of the internet has in turn triggered the explosion of organizations- many unaccredited-purporting to provide a very sound education for you within the comfort of your home! And they are getting bolder! A few years ago when these charlatans started they knew better than to offer courses in healthcare. Now they have become super emboldened. Optometry, radiography, pharmacy and nursing are now offered! How on earth can qualifications in these fields be achieved without hands on experience? I fear for the global future of healthcare delivery. A hallmark of civilization is a clear cut division of labour. This present tolerance for and celebration of the "Jack of All Trades" philosophy won't end well. Gone are the days when you knew what to expect when you walked into a hospital.

A doctor was a doctor and a nurse was a nurse! Now between the doctor and the nurse the physician assistant and the nurse practitioner have smugly and snugly inserted themselves! The optometrist and orthoptist now think themselves to be ophthalmologists and the radiographer thinks he knows everything the radiologist knows. The physician assistant and nurse practitioner professions arrived in 1965 and ten years later the pharmacist assistant reared its smug head. The creation of all sorts of midlevel "practitioners" and the "upgrading" of their certificates to diplomas, then to associate degrees, then to bachelor degrees then to masters degrees (I hope physician assistants are reading this) is not a healthy development [1-2]. Make no mistake about it: too many cooks do spoil the broth! Open a regular or medical dictionary from a few decades ago and neither "nurse practitioner" nor "physician assistant" are defined therein, as these professions did not then exist. The mid-level professions which did exist then such as optometrist and radiographer have VERY different definitions from those in contemporary dictionaries. The professions have begun to overlap with those of ophthalmologist and radiologist. Ditto the pharmacy technician's inroads into the clearly defined roles of dispenser and the pharmacist of old. The "clinical pharmacist" today has started to show up in the operating theatre and lock horns with the anaesthesiologist and his technician! The non-medical world is not spared the confusion. What a wedge the technician and technologist has put between the electrician and the electrical engineer. A time bomb ticks away! These developments cannot but spell doom! 


\section{Observe how from 1920 to 2020 the Definitions of "Optometrist" and "Radiographer" have changed}

Optometrist \optometry +-istle \One who measures the degree of visual acuity, a refractions'; referring generally to a person without medical training who fits glasses to correct visual defects [3]. PAGE 705 Students Medical Dictionary, 1920 optometrist A practitioner who provides primary eye and vision care, performs eye examinations to detect vision problems, and prescribes corrective lenses to correct those problems. Some optometrists also make and fit eyeglasses, but many leave that job to opticians. An optometrist is a doctor of optometry (OD), not an MD. When an optometrist detects eye disease, the patient may be referred instead to an ophthalmologist, a physician who specializes in evaluating and treating diseases of the eye [4]. PAGE 309, Webster's New World Medical Dictionary, 2008 OPTOMETRY is a health care profession that involves examining the eyes and applicable visual systems for defects or abnormalities as well as the correction of refractive error with glasses or contact lenses and treatment of eye diseases.

Traditionally, the field of optometry began with the primary focus of correcting refractive error through the use of spectacles. Modern-day optometry, however, has evolved through time so that the educational curriculum additionally includes significant training in the diagnosis and management of ocular disease, in most of the countries of the world, where the profession is established and regulated. In 2020 wikipedia it is stated thus-A radiographer uses their expertise and knowledge of patient care, physics, human anatomy, physiology, pathology and radiology to assess patients, develop optimum radiological techniques and evaluate the resulting radiographic media.

\section{From Merely Taking X Rays the Radiographer has in a Hundred Years Graduated to Assessor and Evaluator!!}

\section{Is there a Doctor in the house?}

Gone are the days when anyone going by the title "doctor" was either a medical doctor or an academic doctor (a PhD/DSc/ DLitt). Now everyone's a doctor. Optometrists are DO (Doctor of Optometry), nurses are DNP (doctor of nursing practice) and hitherto easy going physiotherapists are calling themselves DPT (doctor of physical therapy). Even the barber-surgeons in the 1700s didn't call themselves doctors! Now pharmacists, nurse practitioners, physician assistants and even psychologists (yes, psychologists NOT psychiatrists) are writing prescriptions! It's hard to remember there was a time when only medical doctors were allowed to write prescriptions.

\section{References}

1. Mister SA (2017) Returning the Physician Assistant Profession to its Roots Could Ease the Tension; Reduce Animosity between Physician Assistants and Others. Meanwhile, a Third World Country Needs Physician Assistants. JOJ Nurse Health Care 4(1):555-630.

2. James F Cawley (2016) Origins of the Physician Assistant Movement in the United States, MPH, PA-C Professor and Vice Chair Department of Prevention and Community Health School of Public Health and Health Services The George Washington University, Bulletin of the History of Medicine.

3. Thomas Lathrop Stedman (1920) A PRACTICAL MEDICAL DICTIONARY Of Words used in Medicine with Their Derivation and Pronunciation, Including Dental, Veterinary, Chemical, Botanical, Electrical, Life Insurance and Other Special Terms; Anatomical Tables of the , Titles in General Use, and Those Sanctioned by the Basle Anatomical Convention; Pharmaceutical Preparations, Official in the U.S. and British Pharmacopceias and contained in the national Formulary; Chemical and Therapeutic Information as to Mineral Springs of America and Europe, and Comprehensive Lists of Synonyms.

4. (2008) Webster's New World Medical Dictionary. ( $3^{\text {rd }}$ edn.).

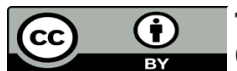

This work is licensed under Creative Commons Attribution 4.0 License

To Submit Your Article Click Here: Submit Article
DOI: $10.32474 /$ LOJPCR.2020.02.000135

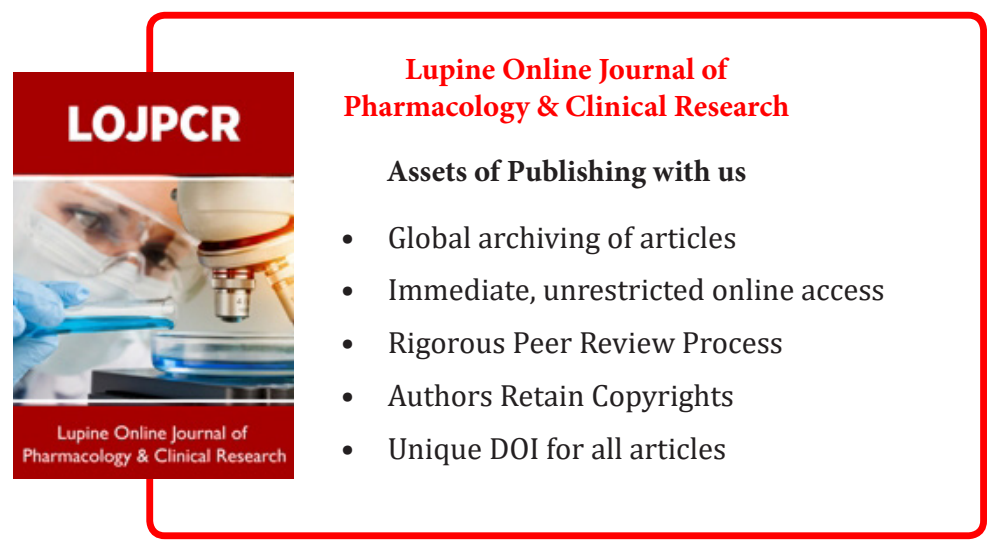

